\title{
Incidence of hyperostosis frontalis interna in patients at a general hospital and at a mental hospital
}

\author{
T. D. HAWKINS AND LAURENCE MARTIN
}

From Addenbrooke's Hospital, Cambridge

Hyperostosis frontalis interna is a curious abnormality of the inner tables of the frontal bones of the skull, said to have been first described by Morgagni in 1751. It consists of aggregations of smooth, rounded enostoses which are covered by dura mater and project into the cranial cavity. Most are about 0.5 to $1.0 \mathrm{~cm}$. in diameter at their bases and attain a similar height. The enostoses do not encroach upon the midline nor, as a rule, extend posteriorly beyond the coronal suture (Figs. 1 and 2). Despite a voluminous literature very little is known about hyperostosis frontalis interna. Thus its mode of formation and growth is unknown, the incidence among the general population is uncertain, and the question as to whether it is merely an anatomical anomaly or a pathological lesion remains unanswered. The striking appearances of hyperostosis frontalis interna, first at necropsies and later in radiographs of the skull, naturally led to attempts to link it with symptoms which have coexisted in affected individuals. Two syndromes have been described in association with it, namely, Morgagni's syndrome, sponsored by Henschen (1949), consisting of hyperostosis frontalis interna, virilism, and obesity in women, and the Stewart-Morel syndrome (Stewart, 1928; Morel, 1930), comprising hyperostosis frontalis interna, obesity, and neuropsychiatric disorders. But neither of these syndromes has been generally accepted, nor has its designation as a 'metabolic craniopathy' by Grollman and Rousseau (1944). We have been unable to find recorded any radiological survey designed to seek or which shows the incidence of hyperostosis frontalis interna in the general population. Those reported have been concerned with the incidence in small selected groups of men or women or in the inmates of mental hospitals. The only information which emerges is that hyperostosis frontalis interna appears to be commoner in women than in men, and in elderly women than in younger. Caughey (1952) has also shown a high incidence in patients of both sexes suffering from dystrophia myotonica and Moore (1952) described its association with acromegaly.

The main objects of this radiological survey were to determine the incidence of hyperostosis frontalis interna among patients at a general hospital and at a mental hospital and to seek confirmation that it was commoner in women as age advanced. A subsidiary object was to obtain evidence as to whether hyper-

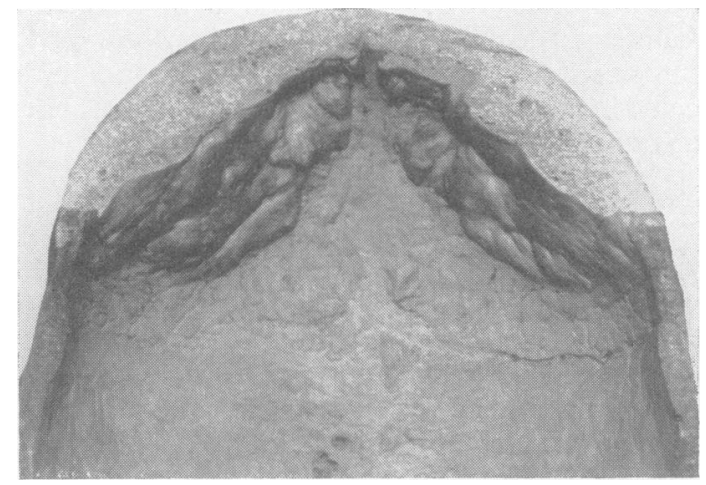

FIG. 1. Photograph of the inner aspect of the frontal bone of a museum specimen showing hyperostosis frontalis interna. The enostoses do not involve the midline nor extend beyond the coronal sutures.

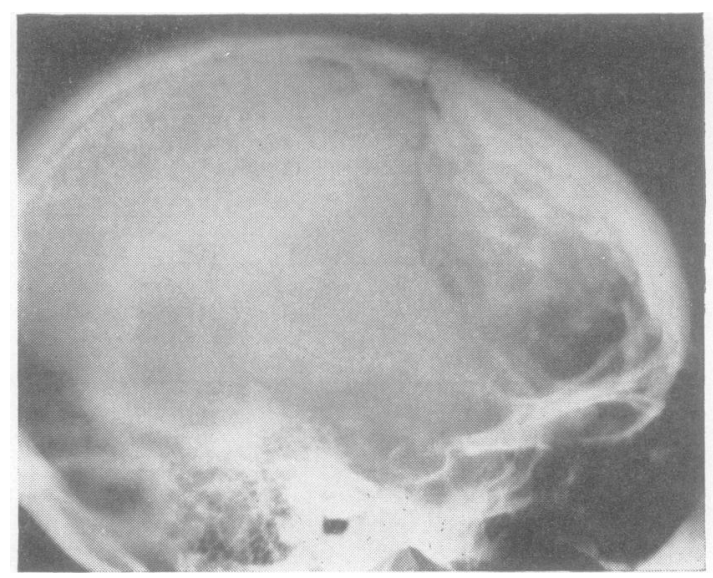

FIG. 2. Lateral radiograph of skull showing marked hyperostosis frontalis interna. 
ostosis frontalis interna appeared to be associated with any particular diseases.

\section{METHODS AND MATERIAL}

Because it was impracticable to carry out a radiological survey of the skulls of a large number of the general population on the lines of mass radiography of the chest, a retrospective survey was made of all the skull films of adults taken at Addenbrooke's Hospital during the years 1959-61. A substantial number had been taken on account of trauma and, of those taken for the diagnosis or exclusion of various diseases, none would have been requested for possible hyperostosis frontalis interna. It was considered that these films would be representative of the skulls of the general population in the area of East Anglia served by the hospital. We also carried out a radiological survey of the adult inmates of Fulbourn Mental Hospital, Cambridge, during the summer of 1963. All patients who consented and who could cooperate sufficiently were radiographed, amounting to about $90 \%$ of the in-patients.

\section{RESULTS}

ADDENBROOKE'S HOSPITAL SERIES A total of 1,318 sets of skull radiographs (lateral, postero-anterior, and semiaxial) taken during the years 1959-61 were examined. Those taken during 1961 (449 males and 336 females) showed that hyperostosis frontalis interna was present in two males $(0.45 \%)$ and in 20 females $(5.9 \%)$. The difference was statistically highly significant $(0.001>P)$ and enabled us to establish the fact that hyperostosis frontalis interna was rare in males as compared with females. The survey was therefore continued with films from females only taken during the years 1960 and 1959.
Table 1 shows an overall incidence of hyperostosis frontalis interna in $51(5.85 \%)$ of the 869 female skull radiographs taken during the three years, with consistent annual incidences of $6.4 \%$ for 1959 , $5.4 \%$ for 1960 , and $5.9 \%$ for 1961 . Figure 3, based upon the figures set out in Table I, confirms that it rises sharply with age.

FULBOURN MENTAL HOSPITAL SERIES A total of 713 in-patients (246 males and 467 females) were radiographed. Hyperostosis frontalis interna was not found in any of the males, confirming the rarity of the condition among men, but it was present in 50 $(10.7 \%)$ of the women (Table I). Figure 4 shows the rising incidence of hyperostosis frontalis interna with age as in the Addenbrooke's patients.

We concluded, therefore, that hyperostosis frontalis interna was rare among males, both in the general and mental hospital patients, and that there was a considerably greater incidence among females, which rose with age. The possible reasons for the higher incidence $(10.7 \%)$ among the female mental iv hospital patients than among the female general hospital patients $(5.85 \%)$ is discussed below.

ASSOCIATION OF HYPEROSTOSIS FRONTALIS INTERNG WITH PARTICULAR DISEASES To investigate the possible association of hyperostosis frontalis interng with any particular diseases, control groups, matchee for age, were selected by random sampling numbers from the patients at both hospitals whose skuIt films were negative for hyperostosis frontalis interna. The Addenbrooke's Hospital controls were also selected from the same year, and those at Fulbourn Hospital from the same ward as the corresponding hyperostosis frontalis interna positives. Tables II and III show the grouped diagnoses of the Addenbrooke's and Fulbourn hyperostosis frontalis

TABLE I

INCIDENCE OF HYPEROSTOSIS FRONTALIS INTERNA IN FEMALE PATIENTS BY AGE AT ADDENBROOKE'S HOSPITAL AND FULBOURN MENTAL HOSPITAL

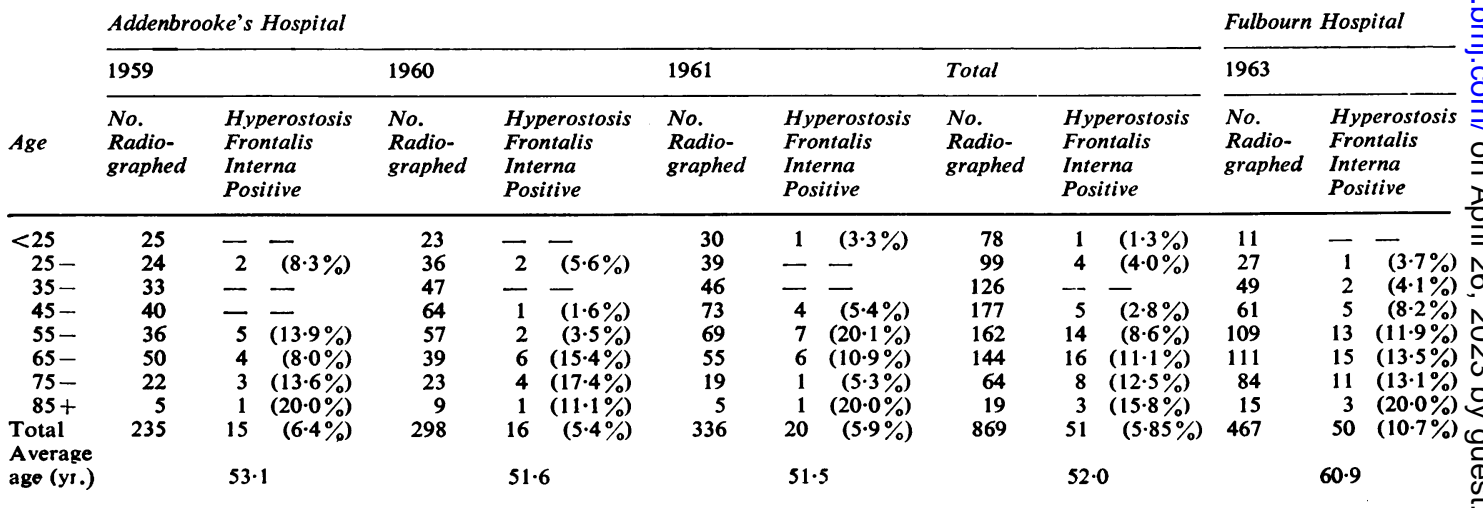



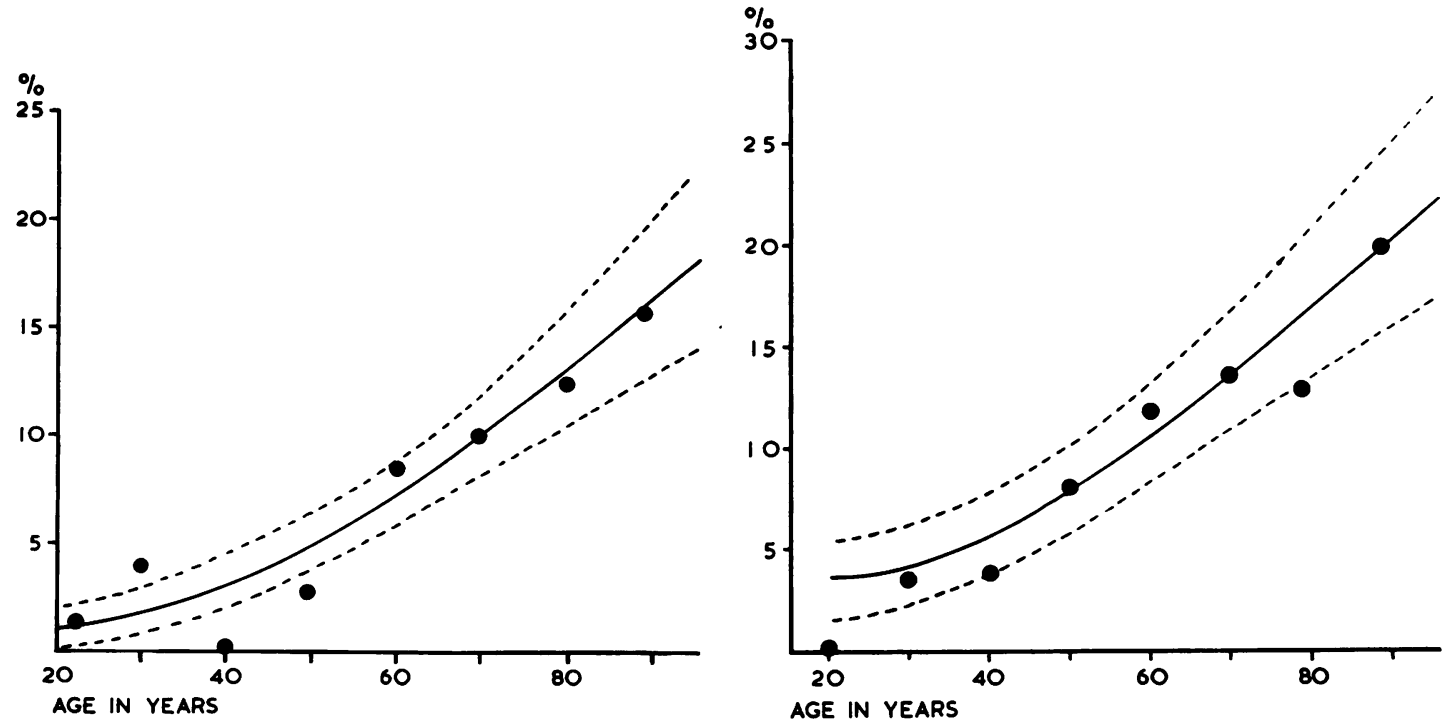

FIG. 3.

FIG. 4.

FIGS. 3 and 4. Incidence of hyperostosis frontalis interna by 10-year age groups in Addenbrooke's (3) and Fulbourn (4) series. are observed points, _- estimated percentage positive by age in both populations, - . - . - 95\% confidence limits. Observed points follow the fitted curves closely: no deviations are statistically significant.

interna positive patients and controls. There is no significant difference between the diagnoses in the positive and control cases of either group. This is hardly surprising, since the reasons for radiographing the skulls of patients at a general hospital are limited to trauma and for the diagnosis or exclusion of a relatively small number of neurological, endocrine, bony, or malignant diseases. Similarly, patients at a mental hospital suffer from relatively few chronic mental diseases. But trauma was the commonest indication for a skull radiograph both in the positives and controls at Addenbrooke's Hospital, which does not suggest that hyperostosis frontalis interna was a cause of symptoms.

\section{DISCUSSION}

The only radiological survey for hyperostosis frontalis interna which is approximately comparable with our present one in respect of general hospital patients is that of Salmi, Voutilainen, Holsti, and Unnérus (1962) carried out at Helsinki. Their series comprised 146 girls and 186 boys aged 15 to 20 years, 249 sexually mature women (most of them pregnant), 253 post-fertile women, 29 old men, and 119 men radiographed on account of trauma. The incidence of hyperostosis frontalis interna among the 334 males was $0.59 \%$, which is similar to our finding of $0.45 \%$. The incidence of hyperostosis frontalis interna among their 648 females was $6.8 \%$, which is
TABLE II

DIAGNOSTIC CLASSIFICATION OF 51 FEMALE ADDENBROOKE'S HOSPITAL PATIENTS POSITIVE FOR HYPEROSTOSIS FRONTALIS INTERNA AND 51 MATCHED NEGATIVE CONTROLS

\begin{tabular}{lcc} 
& \multicolumn{2}{c}{ Hyperostosis } \\
\cline { 2 - 3 } Diagnosis & Positive & Negative \\
\hline Trauma & 17 & 20 \\
Malignant disease & 7 & 5 \\
Disease of central nervous system & 15 & 13 \\
Epilepsy & 1 & 4 \\
Psychiatric & 4 & 3 \\
Others & 7 & 6 \\
Total & 51 & 51
\end{tabular}

Grouping epilepsy with psychiatric cases, $\chi^{2}(4$ degrees of freedom) $=$ $1 \cdot 130 ; 0.9>P>0.8$

TABLE III

DiAGNOSTIC CLASSIFICATION OF 50 FEMALE FULBOURN HOSPITAL PATIENTS POSITIVE FOR HYPEROSTOSIS FRONTALIS INTERNA AND 50 MATCHED NEGATIVE CONTROLS

\begin{tabular}{|c|c|c|}
\hline \multirow[b]{2}{*}{ Diagnosis } & \multicolumn{2}{|c|}{ Hyperostosis Frontalis Interna } \\
\hline & Positive & Negative \\
\hline Schizophrenia & 23 & 19 \\
\hline Manic depressive psychosis & 14 & 17 \\
\hline Senile & 7 & 5 \\
\hline Mental deficiency \pm other psychosis & 2 & 3 \\
\hline Psychosis of physical aetiology & 1 & 5 \\
\hline Other psychoses & 3 & 1 \\
\hline Total & 50 & 50 \\
\hline
\end{tabular}

Grouping the last three diagnoses together, $x^{2}$ (3 degrees of freedom) $=$ $1.605 ; 0.7>P>0.5$ 
also similar to our incidence of $5.85 \%$ in the Addenbrooke's Hospital female patients. Of their females who were positive (44), six were among the adolescent girls, 11 among the sexually mature women, and 27 among the post-fertile women, giving incidences in the three classes of $3.4,4 \cdot 8$, and $10.7 \%$ respectively and so confirming the rise in incidence of hyperostosis frontalis interna with age.

We know of no other series of skull radiographs from a mental hospital comparable in size with our survey at Fulbourn Hospital. Eldridge and Holm (1940) reported the finding of hyperostosis frontalis interna in 50 of 200 consecutive skull radiographs from white or coloured female patients aged 23 to 87 years admitted to a mental hospital at Washington, D.C., giving an incidence of $25 \%$. But 24 of the positive cases were under the age of 50 and 26 above, which is at variance with the findings of Salmi et al. (1962) and ourselves in respect of the increasing incidence with age in women.

Our finding of a different incidence of hyperostosis frontalis interna among the female patients at Addenbrooke's Hospital (5.85\%) and at Fulbourn Mental Hospital $(10.7 \%)$ requires some comment. Part of it was certainly due to the higher average age of the Fulbourn patients (60.9 years) than of the Addenbrooke's patients (52.0 years). But when this age difference was allowed for by an analysis of covariance the average incidence of hyperostosis frontalis interna among the Fulbourn patients was still $3.1 \%$ (s.e. $1.3 \%$ ) higher. This difference is statistically significant $(0.05>P>0.01)$ and although small when expressed as a percentage of the two populations, it appears more important when expressed as an excess by age-groups. Thus there is an excess incidence of hyperostosis frontalis interna among the Fulbourn over the Addenbrooke's patients of $100 \%$ at the age of $20,50 \%$ at 55 years, and $25 \%$ at 90 years (Figs. 3 and 4 ).

These figures might well be interpreted as suggesting an association of hyperostosis frontalis interna with chronic mental disease, as frequently happened in the past. But it must be remembered that in the days before skull radiography was possible, reports of hyperostosis frontalis interna mainly originated from necropsy findings at mental hospitals where, perhaps, greater attention was paid to the skull than in necropsies at general hospitals. Greig (1928) made this point and remarked that the finding of hyperostosis frontalis interna 'was doubtless welcomed as an occasional solution of the mystery of insanity'. We hesitate to theorise on the significance of this observed difference in incidence of hyperostosis frontalis interna in the two groups of patients because neither its causes nor those of many chronic mental diseases are known. We are, however, satis- fied from various tests, under statistical advice, for observer error and the reproducibility of our results that our film-reading was consistent. But we cannot claim to have eliminated altogether the possibility that some skull films showing minimal positive indication of hyperostosis frontalis interna in the Addenbrooke's series might have been classed as negative. This is because minimal manifestations amount to no more than a few very small excrescences on the frontal bones of the skull which cannot be certainly recognized by existing radiological techniques. We therefore record the different incidence of hyperostosis frontalis interna in the general and mental hospital patients as being statistically significant but not capable of explanation.

\section{SUMMARY}

A retrospective survey of the skull radiographs of 449 men and 869 women at Addenbrooke's Hospital taken during the years 1959-61 showed an incidence of hyperostosis frontalis interna of $0.45 \%$ in men and $5.85 \%$ in women, and a similar survey of 246 men and 467 women at Fulbourn Mental Hospital in 1963 showed no incidence of hyperostosis frontalis interna in men and one of $10.7 \%$ in women. The incidence in women increased sharply with age ie patients from both hospitals.

The disease diagnoses in patients from bot hospitals who showed hyperostosis frontalis interna of did not differ from those of matched controls.

This survey does not explain the different incidence of hyperostosis frontalis interna in the general and mental hospital patients.

We are most grateful to Mr. R. G. Carpenter, Statistician to the Medical School, Cambridge University, for his help and to Dr. D. H. Clark, Medical Superintendent of Fulbourn Hospital, for permitting part of the survey, and to the United Cambridge Hospitals for an expenses grant.

\section{REFERENCES}

Caughey, J. E. (1952). Bone changes in the skull in dystrophia myotonica. J. Bone Jt Surg., 34B, 343-351.

Eldridge, W. W., and Holm, G. A. (1940). The incidence of hyperostosis frontalis interna in female patients admitted to a mental hospital. Amer. J. Roentgenol., 43, 356-359.

Greig, D. M. (1928). On intracranial osteophytes. Edinb. med. J., $35,165-191$, and $237-260$.

Grollman, A., and Rousseau, J. P. (1944). Metabolic craniopathy; a clinical and roentgenologic study of so-called hyperostosis $T$ frontalis interna. J. Amer. med. Ass., 126, 213-217.

Henschen, F. (1949). Morgagni's Syndrome. Oliver and Boyd, Edin- N burgh and London.

Moore, S. (1952). Acromegaly and contrasting conditions; notes on $\mathrm{N}$ roentgenography of the skull. Amer.J. Roentgenol., 68, 565-569.

Morel, F. (1930). L'Hyperostose Frontale interne. Doin, Paris.

Salmi, A., Voutilainen, A., Holsti, L. R., and Unnérus, C-E. (1962), Hyperostosis cranii in a normal population. Amer. J. Roentgenol., 87, 1032-1040.

Stewart, R. M. (1928). Localised cranial hyperostosis in the insane. J. Neurol. Psychopath. 8. 321-331. 